\title{
Male and female genital lichen sclerosus. Clinical and functional classification criteria
}

\author{
Alessandra Latini ${ }^{1}$, Carlo Cota $^{2}$, Diego Orsini ${ }^{1}$, Antonio Cristaudo ${ }^{1}$, Marinella Tedesco $^{3}$ \\ IInfectious Dermatology and Allergology Unit (STI/HIV Unit) San Gallicano Dermatological Institute, IRCCS, Rome, Italy \\ ${ }^{2}$ Department of Dermatopathology, San Gallicano Dermatological Institute, IRCCS Rome, Italy \\ ${ }^{3}$ Department of Plastic and Reconstructive Surgery, San Gallicano Dermatological Institute, IRCCS Rome, Italy
}

Adv Dermatol Allergol 2018; XXXV (5): 447-453

DOI: https://doi.org/10.5114/ada.2018.77236

\begin{abstract}
Introduction: Lichen sclerosus (LS) is a chronic inflammatory disease affecting mainly the genital mucous membranes in both sexes. In the past, different terms were used to describe the disease, rendering a unique and specific clinical classification impossible.

Aim: New therapeutic approaches are being defined, which may contribute to a proper clinical management, however, a stage classification is essential to better define appropriate treatment for every stage of the disease. Material and methods: One hundred and fifteen patients (50 women and 65 men) with a diagnosis of LS were enrolled between January 2014 and September 2016. All patients underwent cutaneous biopsy to confirm the clinical diagnosis of LS. Clinical and symptomatological parameters were used in order to put the patients into the correct stage of LS. The Dermatology Life Quality Index (DLQI) was used to classify patients based on subjective symptoms. Different cutaneous alterations and structural modifications of the genital mucosa were also taken into consideration in order to assign every patient to a specific stage.

Conclusions: Lichen sclerosus is clinically described differently in females and in males and every form of LS is put into one of two stages according to the degree of severity: early and late stages. Within the clinical practice, it is useful to screen patients for groups of early or late forms of the disease in order to obtain a uniform subdivision of patients: those who may benefit from localized treatments, require a systemic drug and must undergo physical treatments (surgical, stem cells infiltrations).
\end{abstract}

Key words: clinical staging, classification, diagnosis, lichen sclerosus, prognosis, treatment criteria.

\section{Introduction}

Lichen sclerosus (LS) is a chronic inflammatory disease with an uncertain etiology, affecting mainly the genital mucous membranes in both sexes. It is more frequently observed among women, with a male to female ratio $(\mathrm{M}: \mathrm{F})$ which varies between $1: 3$ and $1: 5$ [1]. The first descriptions of LS date back to the late 1800s and since then many terms have been used to define the disease (Table 1) [2-10].

Throughout the twentieth century, the international literature described LS using several definitions related to the clinical presentation of the disease in different studies (i.e. scleroderma circumscribed, leukoplakic vulvitis, primary atrophic vulvitis or balanitis, bullous lichen planus and atrophic chronic acrodermatitis, atrophic bullous scleroderma). For many decades, these descriptions have limited the development of standardized criteria for a useful and accurate management of LS.

Towards the end of the 1970s, the International Society for the study of Vulvar Disease $[9,10]$ finally coined the term lichen sclerosus to describe this pathology.

Lichen sclerosus mainly affects the genital mucosa and may be located or extended to the oral mucosa, even if the simultaneous involvement of both sites is not frequently observed $[11,12]$. The disease leads to progressive alteration of the four main functions of the mucous tissue: hydration, elasticity, ability to resist mechanical stimulation and proprioceptive transmission. These changes explain most of the symptoms of the disease, which worsen over time and are associated with the destruction of the anatomic structures of the genital region in an advanced stage in both sexes.

Address for correspondence: Diego Orsini MD, Infectious Dermatology and Allergology Unit (STI/HIV Unit) San Gallicano Dermatological Institute, IRCCS, Via Elio Chianesi 52, 00123 Rome, Italy, phone: +39 335/1774185, e-mail: diegorsini@gmail.com Received: 6.11.2017, accepted: 4.12.2017. 
Table 1. Definitions of lichen sclerosus in the scientific literature from 1800 to 1900

\begin{tabular}{lccc}
\hline Definition & Author & Year & Ref. \\
\hline Vulvar and oral ichthyosis & Weir & 1875 & {$[1]$} \\
\hline Craurosis of vulva & Breisky & 1885 & {$[2]$} \\
\hline Lichen planus atroficus & Hallopeau & 1887 & {$[3]$} \\
\hline Lichen planus sclerosus & Darier & 1892 & {$[4]$} \\
\hline Playing card scleroderma & Unna & 1894 & {$[5]$} \\
\hline Disease white spot & Westberg & 1901 & {$[6]$} \\
\hline Lichen albus & Von Zumbusch & 1906 & {$[7]$} \\
\hline $\begin{array}{l}\text { Lichen planus sclerosus } \\
\text { and atrophicus }\end{array}$ & Montgomery & 1907 & {$[8]$} \\
\hline $\begin{array}{l}\text { Dermatitis lichenoides } \\
\text { cronic atroficus }\end{array}$ & \& Ormsby & & \\
\hline $\begin{array}{l}\text { Balanite xerotica } \\
\text { obliterans }\end{array}$ & Stuhmer & 1928 & {$[10]$} \\
\hline
\end{tabular}

In clinical practice, the spectrum of symptoms of LS seems closely related to different phases of the disease [13].

Lichen sclerosus has different clinical pictures in the two sexes for the anatomical differences that exist in the male and female and also subjective symptoms are differently reported by different patients, often regardless of the severity of the disease.

For this reason it is often necessary to manage the initial stages of LS as if they were the most advanced stages of the disease, especially when the subjective symptoms do not correlate with the clinical picture. Furthermore, prognostic studies have shown that if LS is detected early and advanced therapy is started, it responds better to conventional therapies $[14,15]$ with consequent minor anatomic-functional sequelae and a lower risk of neoplastic transformation [16].

In our daily experience we have noticed that there are different stages of evolution of the disease but their identification is not always easy due to the variability of LS clinical presentations and because of the variability of symptoms reported by different patients. Furthermore, every stage of the disease could benefit from different therapeutic approaches: topical loco-regional therapies with emollients and steroid creams can limit the symptoms in the early phases of LS, while surgical approaches are considered for anatomical and functional alterations of the disease, such as phimosis in men [17-20]. Systemic steroids or other immuno-suppressors are generally prescribed in the most serious and advanced cases of LS, and only when tolerated.

\section{Aim}

In our experience, the earlier the diagnosis of LS is made, the earlier the patient can be given specific therapy. In the past few years, LS has also been treated with stem cells from adipose tissue [22-24] and in our preliminary experience, we observed that patients treated with stem cells in the earlier stages of the disease had a better response than those treated later (work in progress).

\section{Material and methods}

A description of clinical presentations of LS in the different phases has been drafted. The study was carried out at the outpatient department of the Dermatological and Plastic and Reconstructive Surgery Unit of San Gallicano Dermatological Institute IRCCS - IFO of Rome.

The study includes data of 115 patients affected by genital lichen sclerosus, between January 2014 and September 2016.

Fifty patients were female, with a median age of 60 years (range: $0-86$ years, and one nine-month-old patient) and sixty-five patients were male, with a median age of 48 years (range: $17-82$ years).

To better understand the phase of LS we adopted in our Center the following procedures for every patient. During the first visit, all patients underwent a physical examination and a thorough medical history was taken in order to evaluate different levels of damage to the ano-genital area caused by LS (alterations of skin pigmentation, presence of skin fissures, changes of skin elasticity, anatomic alterations). A biopsy was performed for all suspected cases of LS (except for the nine-monthold patient). The clinical appearance and the symptoms were evaluated in order to divide the patients into different stages of genital lichen sclerosus and refer every patient to a specific treatment or specific follow-up.

All patients answered the questions of the Dermatology Life Quality Index (DLQI) [21]. The patients were asked about the impact of their disease and its treatment on their lives. Four main stages were developed based on the answers of the patients.

\section{Clinical description of LS groups}

In early stages, female (Figures $1 \mathrm{~A}, \mathrm{~B}$ ) patients complain of a mild discomfort, such as alterations of local sensitivity most often described as itching or burning, a feeling of tension or excessive sensitivity to touch, also caused by intimate apparel. Upon direct observation, a circumscribed blanching can be observed on one or more restricted areas of the mucosa (vaginal introitus, labia minora, fork). At this initial stage, a clinical diagnosis is difficult to reach, and a histological punch biopsy is considered useful and proposed to the patient.

In males, the first manifestations of LS, which is often the reason for a specialist visit, are color alterations, with hypochromic spots causing a mottled appearance, usually spreading to the foreskin, frenulum or near the top of the glans. The initial subjective symptoms may be limited to mild itching or alteration of local sensitivity, as in women. Pain occurs only rarely. These symptoms some- 

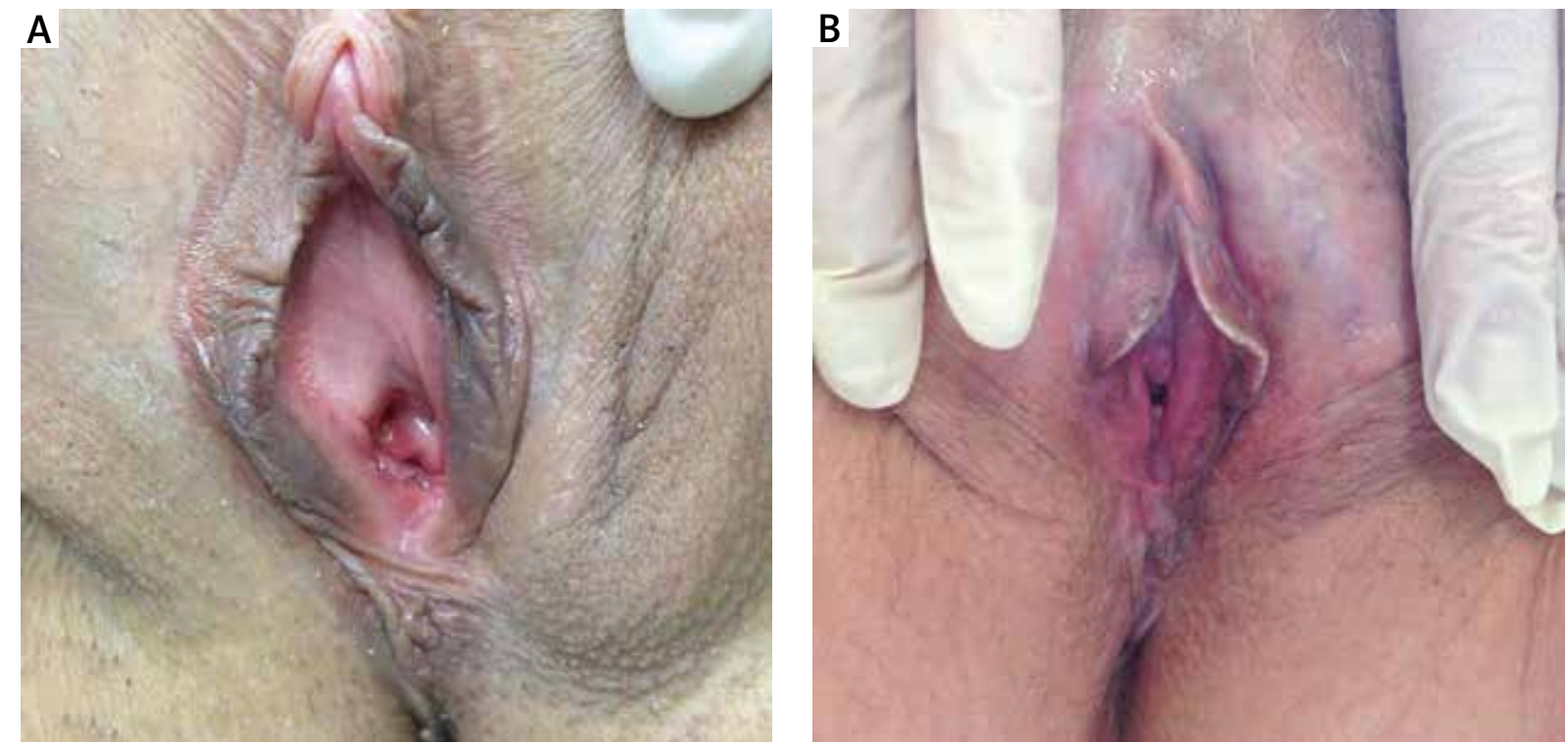

Figure 1. A - Initial atrophy starting from the posterior fork, B - extension of hypotrophy in the minor labia
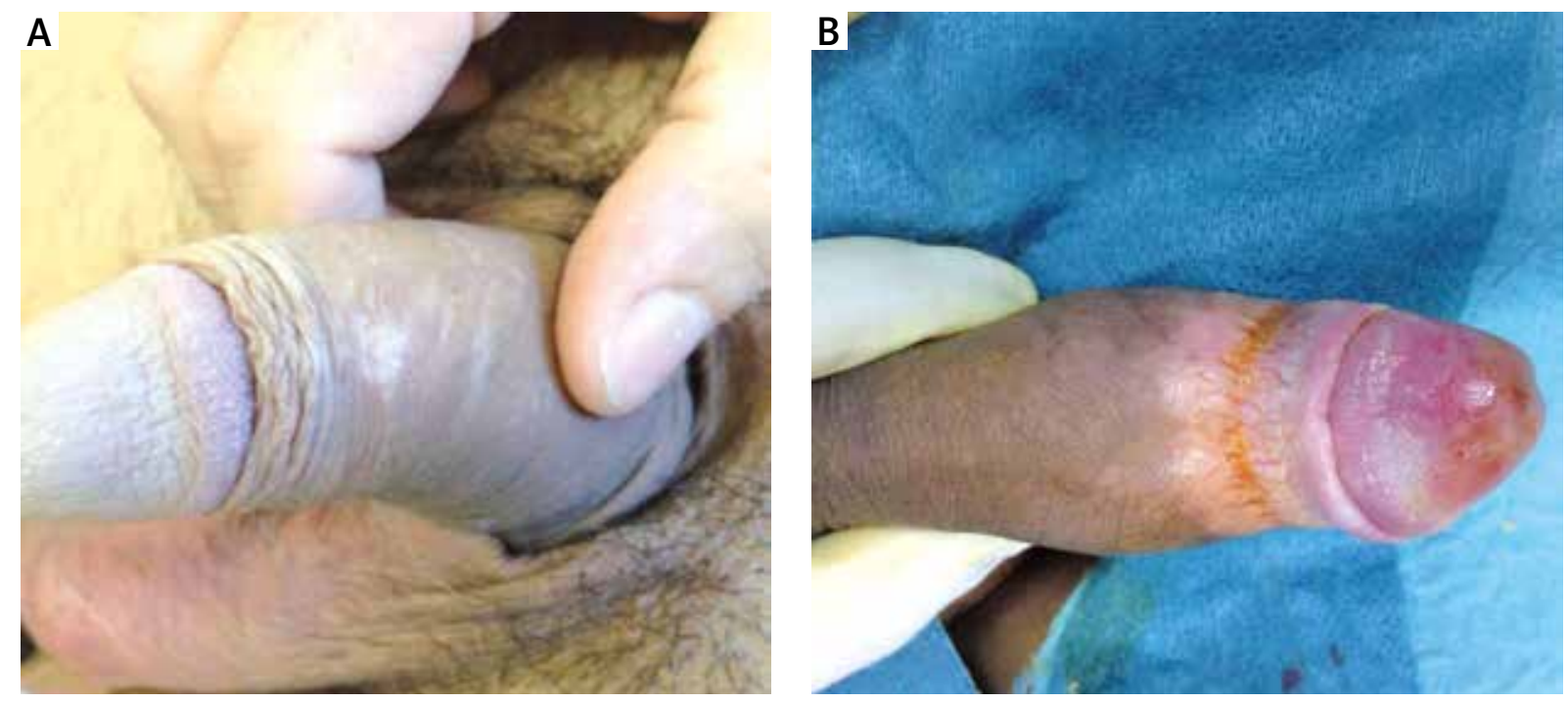

Figure 2. A - Hypochromic spot, B - extension of hypochromic spots with the appearance of mild ring fibrotic

times tend to worsen after sexual activity. At this stage, a clinical diagnosis is very difficult. A common feature of male patients with LS is the short, non-elastic frenulum, which always tends to restrict or distort erection. Often a short frenulum is the only, early manifestation of an initial phase of LS (early stage) (Figures 2 A, B).

In male genitalia the white spots may merge affecting the foreskin as well, which tends to form a non-elastic ring, which may lead to a slight phimosis [20]. In this phase, men complain of a burning sensation and there is an increased risk of infections. At that time, the patients tend to limit sexual activity in order not to aggravate the symptoms but often this is not reported to the special- ists. These clinical and symptomatological aspects make the picture of LS more complex. Subsequently in both sexes fragility of the mucosa to mechanical stimulation appears, especially during sexual activity. Especially in women, the onset of mild dyspareunia and development of fissures resulting from decreased elasticity of the affected areas is described. These cases always need a psychologist's intervention.

In the following more advanced stages, stable fissures appear in addition to the symptoms described above. In women these are frequently located on the posterior fork. Progression of atrophy and fusion of the minor labia takes place as well as atrophy of the major 

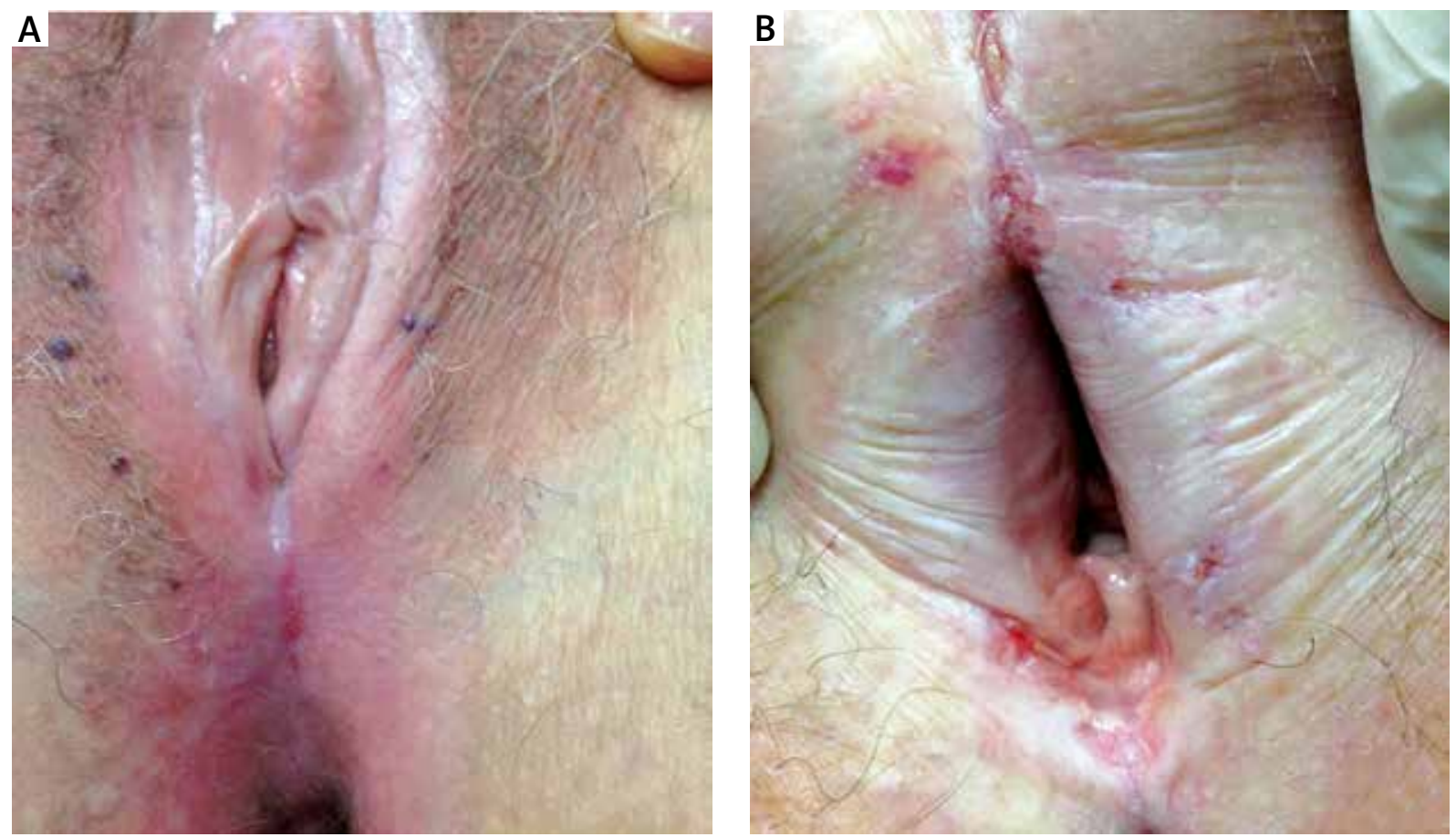

Figure 3. A - Atrophy and fusion of the labia minor, atrophy of the labia major, the clitoral hood is incorporated by sclerotic tissue, and vulvar ostium stenosis, B - disappearance of the clitoris, vaginal ostium stenosis progression, complete disappearance of the labia minora and severe atrophy of the labia majora
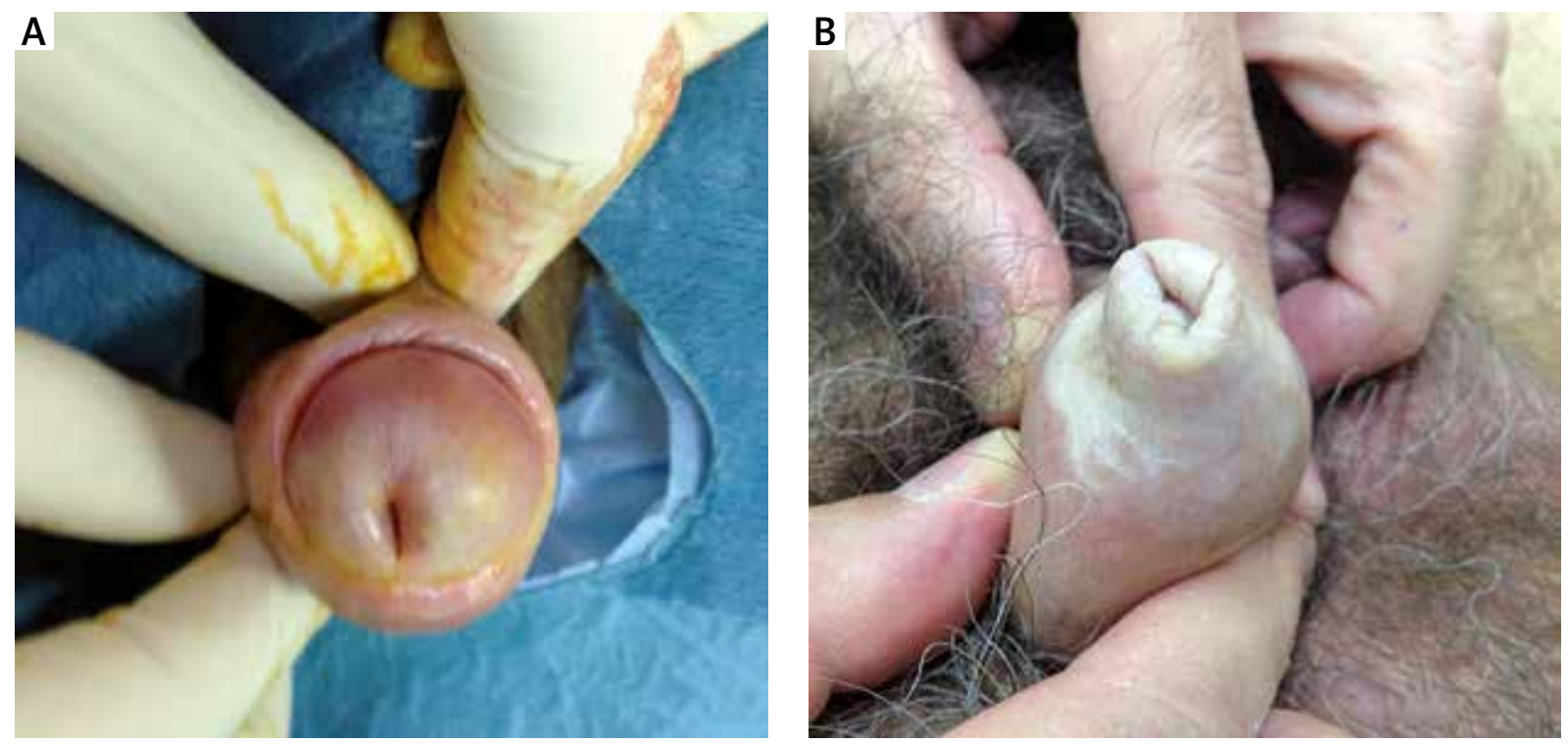

Figure 4. A - Accentuation of the phimosis. Merger of the foreskin at the level of balanopreputial sulcus and initial urethral stricture, $B$ - tight phimosis

labia (Figure $3 \mathrm{~A}$ ). In this phase, the subjective symptoms are associated with neurosensory disorders, such as itching, burning and pain to the touch (allodynia) regardless of sexual activity. These symptoms are also present while walking, standing or sitting. Injuries also affect the clitoral hood that is progressively incorporated by sclerotic tissue, until it is completely covered. An initial vulvar ostium stenosis is present with possible alterations to the urinary meatus, such as urethral stenosis. During this advanced stage, patients also complain of alteration to the flow of urine. In men the extension of sclerotic areas may accentuate the phimosis and the initial appearance 
of urethral stenosis can cause the patients urinary issues (Figures 4 A, B).

In more advanced stages, we have found a complete incorporation with hooding of the clitoris as well as vaginal ostium stenosis progression, complete disappearance of the labia minora and severe atrophy of the labia majora (Figure $3 \mathrm{~B}$ ). In this phase, the entire vulvar region is transformed into extremely fragile sclerotic tissue, which has a tendency for easy fissure throughout the entire genital area. This leads the patient to interrupt sexual activity (apareunia), with urinary difficulties and frequent urinary tract infections. Therefore, their personal life is extremely compromised.

In males, worsening of the sclerosis in the internal tissues of the penile urethra can cause a distal urethral stricture that tends to extend proximally. In more severe cases, urodynamic alterations may worsen. Urethral ste- nosis is more common in men than in women [19]. In these advanced stages it is possible in both sexes to be diagnosed with a squamous cell carcinoma that arises on areas of LS.

A proposed classification in two stages based on clinical and subjective symptoms is presented in Table 2.

\section{Results}

The clinical classification of patients with LS into different groups was essential for an early diagnosis, to put the patients into the correct stage and therefore, prescribe specific treatment options.

By convention in San Gallicano Hospital, we have divided the patients diagnosed with LS broadly into two groups, those with early forms of LS and those with late forms.

Table 2. Proposed classification in two stages

\begin{tabular}{|c|c|c|c|}
\hline $\begin{array}{l}\text { LS } \\
\text { stage }\end{array}$ & $\begin{array}{c}\text { Clinical } \\
\text { characteristics }\end{array}$ & Male & Female \\
\hline \multirow[t]{3}{*}{ Early } & $\begin{array}{l}\text { Subjective } \\
\text { symptoms }\end{array}$ & $\begin{array}{l}\text { Mild itching or alterations of local sensitivity } \\
\text { Burning sensation } \\
\text { Dyspareunia } \\
\text { Pain is rare }\end{array}$ & $\begin{array}{l}\text { Alterations of local sensitivity (e.g. Stinging, burning, } \\
\text { tension, allodynia) } \\
\text { Burning, itching } \\
\text { Dyspareunia }\end{array}$ \\
\hline & $\begin{array}{c}\text { Clinical } \\
\text { examination }\end{array}$ & $\begin{array}{l}\text { Color alterations (hypochromic spots with mottled } \\
\text { appearance) } \\
\text { Short frenulum is highly characteristic } \\
\text { Merging of hypochromic spots with formation of an } \\
\text { inelastic ring responsible of phimosis } \\
\text { Decreased elasticity can lead to painful fissures }\end{array}$ & $\begin{array}{l}\text { Circumscribed blanching (vaginal introitus, labia } \\
\text { minora, fork) } \\
\text { Mucosal fragility to mechanical stimulation } \\
\text { Decreased elasticity can lead to painful fissures }\end{array}$ \\
\hline & $\begin{array}{l}\text { Disease } \\
\text { duration }\end{array}$ & $\begin{array}{l}\text { Difficult to establish; does not always correlate with } \\
\text { disease severity, some cases tend to have a more } \\
\text { rapid clinical progression }\end{array}$ & $\begin{array}{l}\text { Difficult to establish; does not always correlate with } \\
\text { disease severity, some cases tend to have a more } \\
\text { rapid clinical progression }\end{array}$ \\
\hline \multirow[t]{4}{*}{ Late } & $\begin{array}{l}\text { Subjective } \\
\text { symptoms }\end{array}$ & $\begin{array}{l}\text { Burning sensation } \\
\text { Dyspareunia } \\
\text { Urinary symptoms } \\
\text { Symptoms at rest } \\
\text { Apareunia } \\
\text { Urodynamic alterations }\end{array}$ & $\begin{array}{l}\text { Burning, itching } \\
\text { Allodynia becomes more severe even without } \\
\text { mechanical stimulation (e.g. standing, walking } \\
\text { or sitting) } \\
\text { Apareunia } \\
\text { Urinary difficulties } \\
\text { Frequent UTIs }\end{array}$ \\
\hline & $\begin{array}{c}\text { Clinical } \\
\text { examination }\end{array}$ & $\begin{array}{l}\text { Stable fissures } \\
\text { Extension of the sclerotic areas with accentuation } \\
\text { of phimosis } \\
\text { Paraphimosis is a possible complication } \\
\text { Mild urethral stenosis } \\
\text { Extension of the sclerotic areas can lead to distal } \\
\text { urethral stricture that tends to extend proximally } \\
\text { Urethral stenosis }\end{array}$ & $\begin{array}{l}\text { Stable fissures, especially on the posterior fork } \\
\text { Diffuse atrophy and fusion/complete disappearance } \\
\text { of the minor labia } \\
\text { Atrophy of the major labia } \\
\text { Clitorial hood is progressively covered by sclerotic } \\
\text { tissue } \\
\text { Vulvar ostium stenosis, possible alterations to the } \\
\text { urinary meatus (e.g. urethral stenosis) } \\
\text { Complete incorporation with hooding of the clitoris } \\
\text { Vaginal ostium stenosis }\end{array}$ \\
\hline & Complications & Squamous cell carcinoma can arise in areas of LS & Squamous cell carcinoma can arise in areas of LS \\
\hline & $\begin{array}{l}\text { Disease } \\
\text { duration }\end{array}$ & $\begin{array}{l}\text { Does not always correlate with disease severity, } \\
\text { some cases tend to have a more rapid clinical } \\
\text { progression than others leading to different clinical } \\
\text { pictures }\end{array}$ & $\begin{array}{l}\text { Does not always correlate with disease severity, } \\
\text { some cases tend to have a more rapid clinical } \\
\text { progression than others leading to different clinical } \\
\text { pictures }\end{array}$ \\
\hline
\end{tabular}


The groups were formed as follows: for women, 17 (34\%) patients were included in earlier stages of the disease, while 33 (66\%) women showed clinical and symptomatological characteristics consistent with the late stages of LS. As for males, 46 (70\%) patients were included in earlier stages, 19 (30\%) were in a very advanced stage of the disease.

The clinical aspects and the symptoms were evaluated in order to assign each patient to a more or less earlier or later stage of the disease.

At the onset of the disease, the symptoms are usually difficult to recognize, and vary from patient to patient. Initial symptoms reported by patients (surface tension, itching, burning and, less often, pain or presence of slight alterations of genitalia as hypochromic mucosal areas) were all taken into consideration. In fact, non-specific symptoms may persist for a long time and patients generally do not refer to a specialist in the initial stages. On the other hand, the overlapping of symptoms may be misleading resulting in a delayed diagnosis.

It is worthy considering that the female population from our series has the diagnosis of LS established later and already presenting more severe clinical forms. In our experience, women have the diagnosis of LS established later in life than men especially in the form of early LS (34\% of women vs. $70 \%$ of men).

Subjective symptoms are differently reported by different patients often regardless of the severity of the disease. The disease is often misunderstood, given it is not always diagnosed in its early stages. Indeed, LS remains the prerogative of various clinical specialists (urologists, gynecologists, dermatologists, pediatricians, plastic surgeons), which is often misleading for patients and delays diagnosis.

In the advanced stages of the disease, subjective symptoms are associated with structural modifications of the genital mucosa. When clinical symptoms are less important (increase in the mucosal and cutaneous dryness, loss of elasticity of the skin) patients not always seek a specialist's help early. Otherwise when the sclerotic aspect predominates subjective symptoms it can lead to extreme surface fragility and tendency to fissure the skin. In these phases, the architecture of the genitalia can be completely transformed with a negative impact on social relationships, sexual intercourse and quality of life [13]. In these advanced stages of LS, people visit the specialist early.

The clinical classification of LS in mainly two stages, early and late, was performed on the basis of the clinical picture and histological aspect confirming diagnosis in very early phases of the disease.

All patients in this study were subjected to punch biopsies of the genital lesions in every clinical stage. In early phases of poor clinical symptoms but where patients complained of more important subjective symptoms (itching, burning, feeling excessive sensitivity to touch), in our experience, the typical histopathologic aspects were already observed even if lightly present. Microscopic examination of $\mathrm{H}+\mathrm{E}$ sections always reveals thickening of epithelium and atrophy of the malpighian stratum variously represented. In the dermis, loss of the elastic fibers is present with edematous hyalinized connective tissue. The perivascular band of lymphocytic infiltrate is present to a variable degree below the edematous stratus. In the more advanced forms of LS, the most important histological aspects include the atrophy of the epidermis, the massive homogenization of the collagen that can be variously associated with a different grade of lymphocytic infiltrate (data not shown). These histopathological features cannot be all represented in all phases of the disease.

In this study we also tried to measure how much LS could affect patients' quality of life. All patients answered the questions of the Dermatology Life Quality Index (DLQI) [20]. The patients were asked about the impact of their disease and its treatment on their lives. Two main groups of severity of LS (early and late disease) were developed based also on the answers of the patients.

Among females with a very early LS diagnosis, 10/17 women (58\%) patients represented the earlier stages with clinical pictures and subjective symptoms associated to a DLQI score between 0 and 11 (from no effects to small/moderate effects on patients' life of the disease). Most female patients (60\%) with a late LS (20/33 women with late LS) presented progression of atrophy and alteration of vulvar anatomy; these pictures are generally associated to very large effects on women's life, especially as to difficulties with sexual partners and had a higher DLQI score (between 11 and 20). 40\% of female patients (13/33 women) with a very late LS clinical form showed serious clinical pictures. In these cases LS had an extremely large effect on the patient's life (DLQI score between 21 and 30 points) and we had to manage these LS variants with psychological support too.

As regards the males, $24.6 \%$ (16/65 men) were diagnosed in our Centre with early LS variants. They all $(100 \%)$ complained of very large effects on their life and had a higher DLQI score (from 11 to 20 points).

Besides, about 61\% (30/49 men) of male patients with a late LS complained of an impaired quality of life. They presented higher DLQI (score from 11 to 20 points), while about $40 \%$ of males with a late LS H (19/49) showed the highest DLQI scores (21-30 points) according to the clinical aspect of important sclerosis, alteration of all penile anatomic structures and urethral stricture until phimosis.

\section{Conclusions}

Classification of the stages of the disease is necessary in order to achieve a uniform subdivision of patients, and to establish who may benefit from localized 
therapy, require systemic drugs or must undergo physical treatment (stem cell infiltrations) [22-24]. Within the clinical practice, staging of LS can be useful to obtain consistent data, control the disease itself and allow for a correct follow-up.

The two-stage classification (early and late disease) for LS is based on clinical and subjective symptoms and anatomical alterations of the genital region. All patients diagnosed with LS and confirmed by a histological examination underwent clinical evaluation, and filled out a questionnaire to measure the extent to which LS limits their quality of life [21].

Patients with severe clinical symptoms (local itching or burning, limit to daily life) and anatomical transformation of the local region (vulvar stenosis, atrophy of labia minor) were classified into more advanced stages. The severity of symptoms, usually, goes hand in hand with structural alterations.

In our experience, most of the patients with the advanced stage of LS are patients older than fifty years of age (in both sexes). The presence of advanced disease reduces the therapeutic options and the treatment response. Therefore, our study emphasizes the importance of early diagnosis of genital lichen sclerosus and the need for further studies in this field.

\section{Conflict of interest}

The authors declare no conflict of interest.

\section{References}

1. Kantere D, Lowhagen GB, Alvengren $\mathrm{G}$, et al. The clinical spectrum of lichen sclerosus in male patients - a retrospective study. Acta Derm Venereol 2014; 94: 542-6.

2. Weir RF. Icthyosis of the tongue and vulva. NY State J Med 1875: 246.

3. Breisky A. Uber Kraurosis vulvae. Z Heilkr 1885; 6: 69.

4. Hallopeau H. Lichen plans scléreux. Ann Derm Syph $\left(2^{\text {nd }}\right.$ series) 1889; 20: 447-9.

5. Darier J. Lichen plans cléreux. Ann Derm Syph 1892; 23: 833-7.

6. Montgomery FH, Ormsby OS. "White spot disease" (morphoea guttata) and lichen planussclerosus et atrophicus. J Cutan Dis 1907; 25: 1-16.

7. Csillag J. Dermatitis lichenoides chronica atrophicans. Ikonographia Dermatol 1909; 4: 147.

8. Stiihmer A. Balanitis xerotica obliterans (post operationem) und ihre beziehungen zur Kraurosis glandis et preaeputii Penis. Arch Derm Syph (Berlin) 1928; 156: 613- 23.

9. Friedrich EG. Lichen sclerosus. J Reprod Med 1976; 17: 147-54.

10. Friedrich EG. New nomenclature for vulvar disease. Obstet Gynecol 1976; 47: 122-4.

11. Leelavathy G, Parmar H, Das JK, Gangopadhyay A. Extragenital lichen sclerosus et atrophicus. Indian J Dermatol 2015; 60: 420.

12. Vazquez MG, Navarra R, Urda MT, et al. Lichen sclerosus et atrophicus with cutaneous distribution simulating lichen planus. Case Rep Dermatol 2010; 2: 55-9.

13. Virgili A, Borghi A, Toni G, et al. Prospective clinical and epidemiologic study of vulvar lichen sclerosus: analysis of prevalence and severity of clinical features, togheter with historical and demographic associations. Dermatology 2014; 228: 542-6.

14. Neill SM, Lewis FM, Tatnall FM, Cox NH. British Association of Dermatologist' guidelines for the management of lichen sclerosus 2010. Br J Dermatol 2010; 163: 672-82.

15. Neill SM, Tatnall FM, Cox NH. Guidelines for the management of lichen sclerosus Br J Dermatol 2002; 147: 640-9.

16. Carlson BC, Hofer MD, Ballek N, et al. Protein markers of malignant potential in penile and vulvar lichen sclerosus. J Urol 2013; 190: 399-406.

17. Goldstein AT, Marinoff SC, Christofer K. Pimecrolimus for the treatment of vulvar lichen sclerosus in a premenarchal girl. J Pediatr Adolesc Gynecol 2004; 17: 35-7.

18. Higgins CA, Cruickshank ME. A population-based casecontrol study of aetiological factors associated with vulvar lichen sclerosus. J Obstet Gynaecol 2012; 32: 271-5.

19. Alvarez-Vijande R. One-step reconstructionof penile urethral strictures. Indications and techniques. Arch Esp Urol 2014; 67: 35-45.

20. Ambrifi M, Dona MG, Tedesco M, et al. Lichen sclerosus in stable sexual partners: etiologic correlation or mere coincidence? G Ital Dermatol Venereol 2017; 152: 92-4.

21. Finlay AY, Khan GK. Dermatology Life Quality Index (DLQI): a simple, practical measure for routine clinical use. Clin Exp Dermatol 1994; 19: 2010-6.

22. Bellei B, Migliano E, Tedesco M, et al. Maximizing non-enzymatic methods for harvesting adipose-derived stem from lipoaspirate: technical considerations and clinical implications for regenerative surgery. Sci Rep 2017; 7: 10015.

23. Casabona F, Priano V, Vallerino V, et al. New surgical approach to lichen sclerosus of the vulva: the role of adiposederived mesenchymal cells and platelet-rich plasma in tissue re generation. Plastic Reconstr Surg 2010; 126: 210e-1e.

24. Onesti GM, Carella S, Ceccarelli S, et al. The use of human adipose-derived stem cells in the treatment of physiological and pathological vulvar dystrophies. Stem Cells Int 2016; 2016: 2561461. 